\title{
Deutiches Qejebuch
}

für

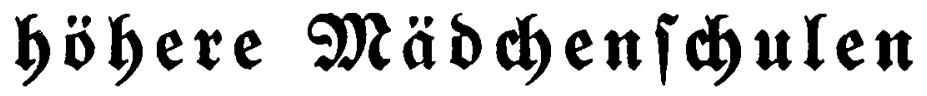

bon

Rarl Gefiel.

\author{
Eriter Teil. \\ Reunte Rlajie.
}

\begin{abstract}
Treizebnte 2uflage,
burchgefeben unter Mitwirfung von Selene Rloftermann uno PMaria Seffel.
\end{abstract}

$\mathfrak{B} \bullet \mathfrak{n n} 1918$.

2. Marcus unb $\mathfrak{E}$. Weberв Berlag. 
